\title{
Predicting Inherited Cancers: the Actuarial Implications
}

\author{
Angus S. Macdonald
}

Department of Actuarial Mathematics, Heriot-Watt University, Riccarton Campus, Edinburgh EH14 4AS, UK

Concerns have been raised about the implications of genetics for insurance and care costs, both from the public's and the insurance industry's points of view. Insurers worry that applicants might have increasingly precise knowledge of their own risks, which will lead to adverse selection. Public worries focus on the creation of a "genetic underclass" that cannot get access to insurance or essential services. The most striking feature about this, often heated, debate is the almost total absence of numerical estimates of the cost implications.

Actuarial modelling is beginning to provide such numerical estimates, in the first instance to the question of the costs of adverse selection if life insurers did not know genetic test results. The answers point to a sharp distinction between dominant single-gene disorders and multifactorial disorders. The former are rare enough that solutions outwith the free market should be sought, and (with some exceptions) the latter probably will not provide clear and reliable estimates of lifetime risk, distinguishable from lifestyle and environmental factors; they might therefore not meet criteria of accuracy and reliability such as those that govern discriminatory pricing in respect of disability. Health and long-term care insurance present more difficult problems, however. 


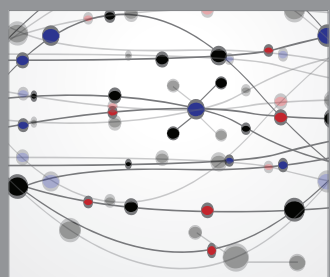

The Scientific World Journal
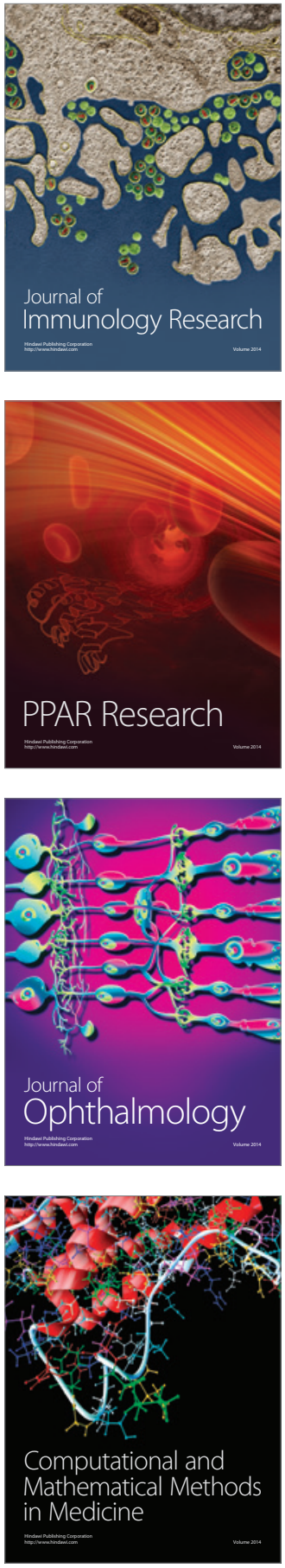

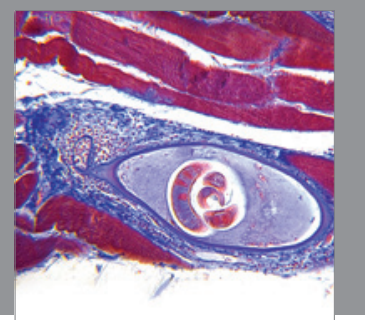

Gastroenterology

Research and Practice
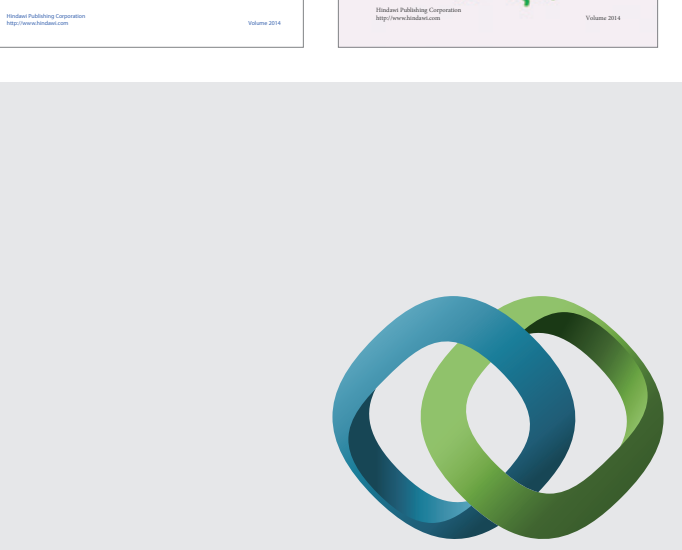

\section{Hindawi}

Submit your manuscripts at

http://www.hindawi.com
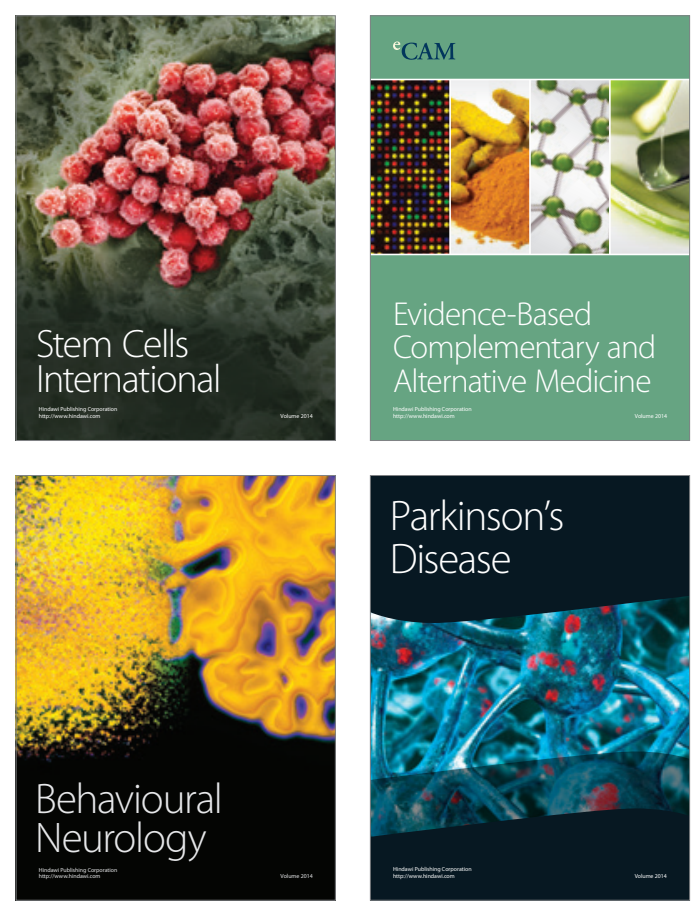

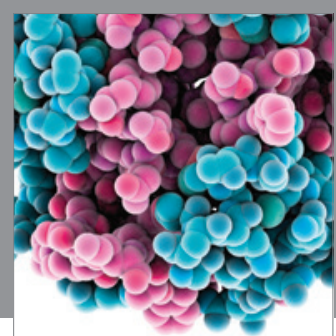

Journal of
Diabetes Research

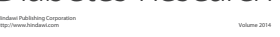

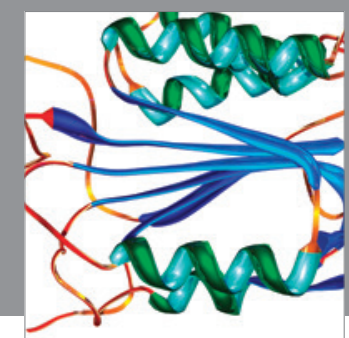

Disease Markers
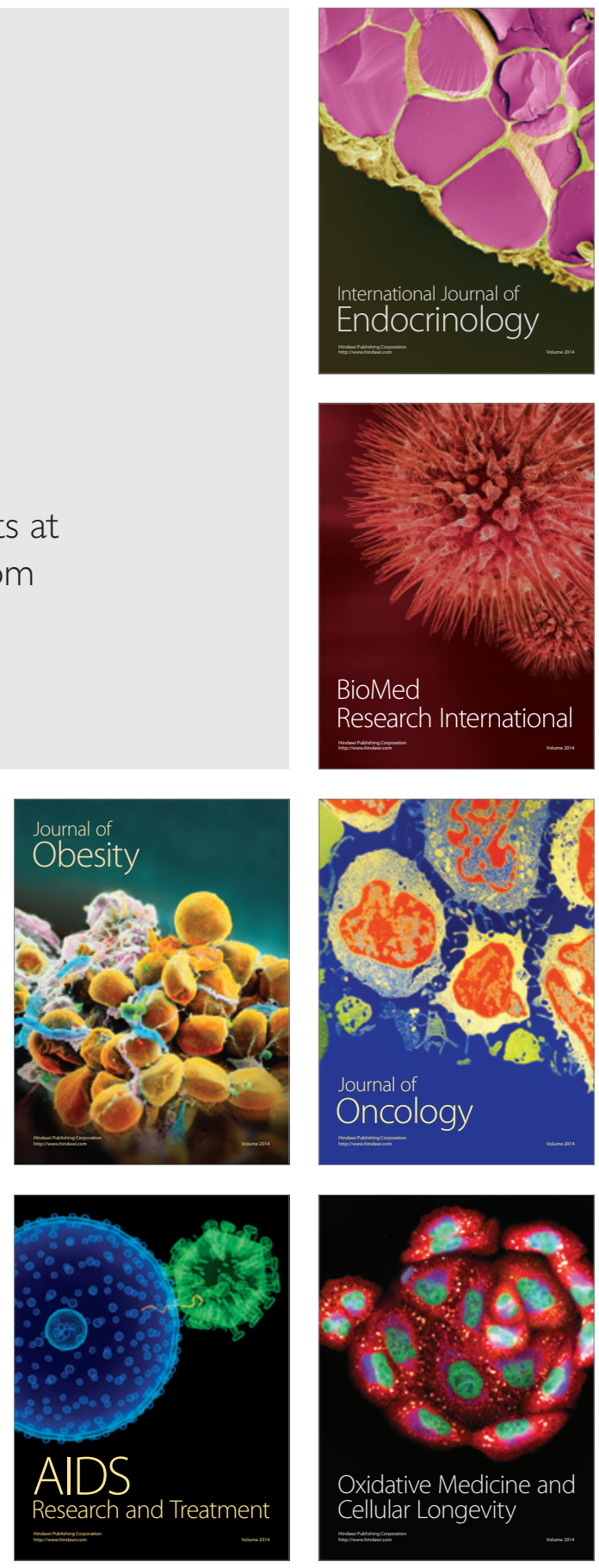